\title{
Gender inequality \& workplace harassment of women in India
}

\begin{abstract}
This paper discusses the Gender Inequaly \& Workplace Harassment of Women in India. Barely a person feel that the Sexual Harassment of Women at workplace (Prevention, Prohibion and Redressal) Act, 2013 is been so val and powerful to the working ladies and the working environment especially in sector, finding a way or solution for punishing such kind of offenses. The objective of this paper is to learn about the sexual harassment against ladies in India and to find the significant reasons of harassment against ladies in workplaces. To break down the adequacy of Sexual Harassment of Women at workplace (Prevention, Prohibion and Redressal) Act, 2013 in controlling the sexual harassment in working environment in India. This demonstration originated from the Vishaka rules. This Research is done by doctrinal type, and utilized secondary sources that are essential and val for data analysis. The secondary sources are collected from on the Internet, articles, other research journals, books and exposed acts in light of the subject. The Research utilized rates for significant investigation of the outcomes. At the point when Women work they are viewed as the change operators for the general public as the ladies are given more significance. The most extreme sexual harassment issue happens in the sectors.
\end{abstract}

Volume 3 Issue 6 - 2019

\section{Sarwade Walmik Kachru}

Department of Management science, Dean Faculty of commerce and Management, Dr. Babasaheb Ambedkar Marathwada University Aurangabad, India

\author{
Correspondence: Sarwade Walmik Kachru, Director, \\ Department of Management science, Dean Faculty of commerce \\ and Management, Dr. Babasaheb Ambedkar Marathwada \\ University Aurangabad, Maharashtra, India, \\ Email maharshtra.commerce@gmail.com
}

Received: July 3, 2019 | Published: November 27, 2019

Keywords: sexual harassment, sector, workplace, prohibion, women

\section{Objectives of the study}

i. To study the current \& past situation of gender difference in India.

ii. To highlight the problem of workplace harassment of working women's in India. ${ }^{1,2}$

iii. To analyze the current situation of gender inequality \& workplace harassment in the country.

\section{Research methodology}

This study is based on descriptive research. Primary data is collected through questioner which is taken from women working in different sectors \& different part of Marathwada region of Maharashtra State, India. The sample size for this study is 40 respondents. Secondary data is collected from various journals and web sites.

\section{Introduction}

Suchitra Rao, a social Worker has communicated her perspectives on ladies in her article, "Ladies in India", in India Today, Sep 2008. There is no uncertainty that we are amidst an incredible transformation ever of. The proof is all over the place; the voice of ladies is progressively heard in Parliament, courts and in the lanes. While ladies in the West needed to battle for over a century to get a portion of their fundamental rights, similar to one side to cast a ballot, the Constitution of India gave ladies equivalent rights with men from the earliest starting point. Lamentably, ladies in this nation are for the most part ignorant of their rights due to lack of education and the severe convention. Names like Kalpana Chawla: The Indian conceived who battled her way up into NASA and was the main ladies in space, and Indira Gandhi: The Iron Woman of India was the Prime Minister of the Nation, Beauty Queens like Aishwarya Rai and Susmita Sen, and Mother Teresa are illustrative of the Indian ladies.

From numerous hundreds of years ladies have thought about optional part in Indian culture. Ladies should do just family work and dealing with their families. They were not permitted to go out for work. They were not permitted to take training. Hundreds of years have passed, however not the reasoning. Today in the period of modernization and globalization, Indian culture is in a phase of fast social progress. Ladies are entering the workforce even in occupations which were recent viewed as solely men's space. Ladies are taught and working similarly to men in each field. In the ongoing years, states of working ladies in India have improved impressively. An ever increasing number of ladies wind up in places of regard and eminence; an ever increasing number of working environments are presently populated with ladies who work on equivalent terms as men. Working is never again a change, a unimportant need; yet a way to self-esteem and development.

\section{Sexual orientation imbalance}

In Indian culture the disparity among people is a standout amongst the most critical variations, which reflects directly from the introduction of the young lady youngster up to death of ladies. Sex imbalance and sex advancement's inquiry moves around the 'control' ladies held. Indian ladies paying little mind to their rank, religion or class; have never appreciated equivalent status in the general public even in their families. Albeit sacred and lawful protections and a few strengthening projects and approaches of their advancement have improved the status of ladies, yet they need control in numerous fields and henceforth they are subordinate to men. The issue of disparity in business being a standout amongst the most problems that needs to be addressed today. The importance of sex uniformity in obvious sense is to give equivalent or same chances to people in different social statuses. One ought not to take wrong importance to contrast sexual orientation balance and sex balance, while the sex equity implies the quantity of guys and females. Sex balance delineates the degree of advancement among people. India is submitted towards thousand year's advancement objectives and exceptional endeavors have been taken by Government to achieve these objectives. Government has presented various projects and activities for 360 degree societal and financial improvement of Indian ladies. 


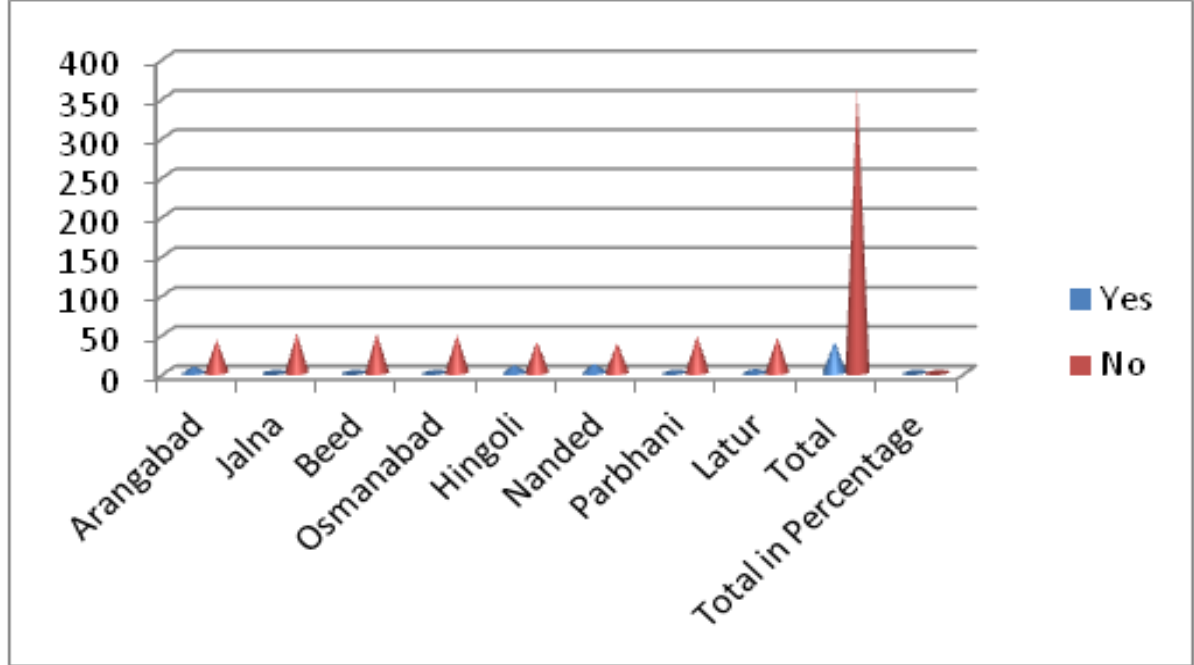

Figure I Opinion of women working in different sectors of Marathwada Region.

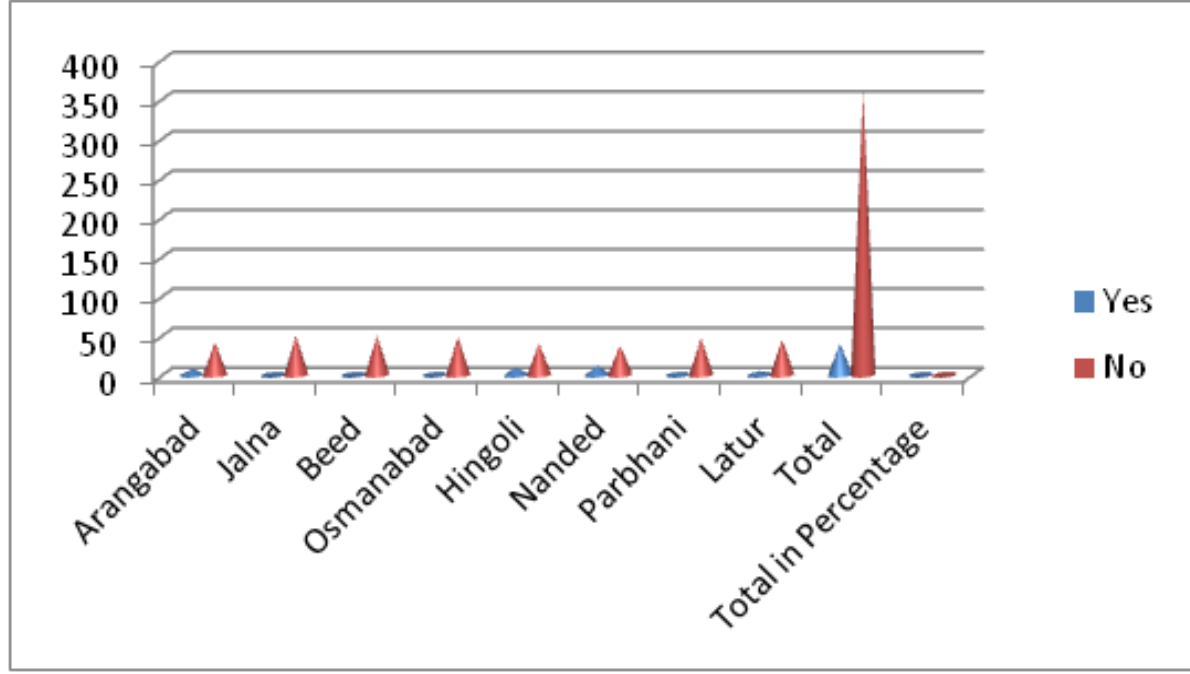

Figure 2 Opinion of women working in different sectors of Marathwada Region.

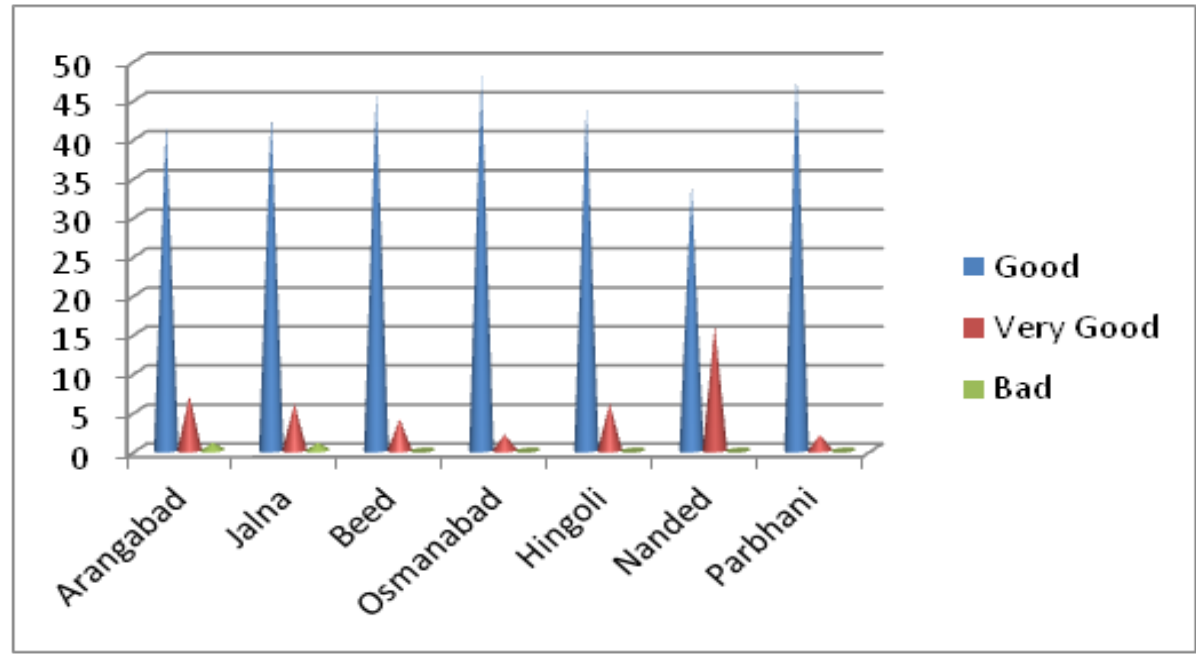

Figure 3 Opinion of women working in different sectors of Marathwada Region regarding Attitude/Behaviors of their male colleagues at Workplace. 


\section{Working environment harassment}

Employees experience a wide scope of badgering practices when they enter the working environment. Representatives experience provocation and brutality in the work environment dependent on numerous grounds. The kind of climate that business accommodate representatives is critical to their physical and passionate prosperity. Tragically a representative can destroy the activity fulfillment of a kindred laborer with inconsiderate and annoying practices. A harasser can participate in somewhat irritating conduct that weakens the others focus or he can perform amazingly repulsive activities that make uneasiness and undermines the security of the other individual. Working environment badgering means taking part in a course of vexatious remarks or direct against a laborer in a working environment that is known or should sensibly to be known to be unwelcome. ${ }^{3}$

Working environment provocation includes practices that add to a threatening workplace. Working environment provocation must incorporate segregation dependent on a secured class status, for example, race, religion, incapacity? Badgering alludes to vexatious conduct experienced because of at least one individual properties, and it is likewise characterized as "Provocation is verbal or physical direct that stigmatizes or shows threatening vibe or revulsion toward an individual on account of his/her race, shading, religion, sexual orientation, national root, age, or inability, or that of his/her relatives, companions, or relates, and that (I) has the reason or the impact of making a scary, antagonistic, or hostile workplace; (ii) has the reason or impact of irrationally meddling with a person's work execution., ${ }^{4,5}$

\section{Sexual orientation and ethnic harassment}

Sex Harassment has been treated as one part of inappropriate behavior, yet dissimilar to sexual pressure or undesirable sexual consideration, it "passes on threatening vibe without any express sexual thought process" Evidence has reliably demonstrated that sex badgering happens more habitually than endeavors to earn sexual participation, and when sexualized types of provocation do happen, they are about constantly combined with sex provocation. Ethnic provocation includes both threatening remarks about focus on person's ethnic gathering and rejection of the objective from business related or social collaborations as a result of the person's ethnicity. Different research reports that analyzed ladies' versus men's lewd behavior encounters shows

a. Non-huge sex contrasts in recurrence rates in certain settings;

b. Parallel factor structures for GH measures for the two sexual orientations, and

c. Sex likenesses in the attack of models looking at the forerunners and results of badgering.

\section{Verbal abuse}

The most continuous sort of discourteous and annoying conduct that happens at work is verbal in nature. Inconsiderate, snide or corrupting comments are discourteous and, if successive can establish provocation. Yelling and the utilization of interjections are types of verbal maltreatment. Any predictable verbal exchange that influences an individual's capacity to work in a quiet domain is discourteous and badgering. Progressing verbal tirades by one representative against another laborer require HR director's mediation. The HR chief must be wary for these practices with the goal that he can caution, guidance and authorization guilty parties.

\section{Verbal abuse by employers}

Verbal maltreatment at the working environment can be delegated inconspicuous maltreatment and obvious maltreatment. Plain verbal maltreatment is the point at which the business affronts the other individual by yelling, ridiculing, undermining, utilizing injurious language, and so forth. The business may choose botches and condemn the person before different representatives. Inconspicuous verbal maltreatment is the point at which the business condemns or passes mocking comments without hollering or yelling. The business may give his representative a chilly treatment, while being pleasant and jolly with others. The business may likewise attempt to maintain a strategic distance from the representative, when he attempts to examine issues and issues. Since this occurs in a private setting, there will be no observers and no other representative will confides in what the mishandled worker is stating and this makes him to diminish his confidence. The manhandled representative has no other choice than leaving the association and makes him disappointed in his activity.

\section{Relations}

Representative counter against another specialist establishes badgering. This can include a chief and a staff part, or can be one representative fighting back against a friend. A director who changes a representative's work routine to threaten the worker can be blamed for provocation. The administrator of an organization must need to decide the legitimacy of any supposed retaliatory conduct and right the circumstance. Track the episode and caution the culprit that this kind of conduct later on will result in suspension or different genuine disciplinary activity.

\section{Inappropriate behavior}

Inappropriate behavior at the work environment is uncontrolled however nobody discusses it. Lewd behavior can extend from profane jokes and comments to wrong contacting and physical attack. Inappropriate behavior in the work environment hurts the objective of abuse. $17 \%$ of working ladies in real urban communities of India have conceded $t$ it. Anyway most the provocation was not physical. An overview done by Oxfam India and the social and provincial research foundation in 2011-2012 demonstrated that high occurrence of lewd behavior occurring in both sorted out and disorderly divisions and ladies are confronting episodes that are non physical. Viciousness against ladies is a human rights infringement be it abusive behavior at home inside homes or inappropriate behavior at working environment. Lewd behavior regularly mirrors a maltreatment of intensity inside an association, where individuals from one gathering of individuals yield more noteworthy power than others, by and large ladies.

\section{Data analysis}

Table 1 shows the opinion of women working in different sectors of Marathwada Region. It shows that, $67 \%$ women do not face any kind of gender difference at their workplace whereas according to $33 \%$ women, they face gender difference at their workplace.

Table 2 shows the opinion of women working in different sectors of Marathwada Region. It shows that, $90 \%$ women do not face any kind of Mental/Physical Harassment at their workplace whereas according to $33 \%$ women, they face some type of Mental/Physical Harassment at their workplace.

Table 3 shows the opinion of women working in different sectors 
of Marathwada Region regarding Attitude/Behaviors of their male colleagues at Workplace. It shows that, $86.25 \%$ women feel that they face good Attitude \& Behaviors of their male colleagues at their workplace and $13.25 \%$ women feel that they face very good Attitude $\&$ Behaviors of their male colleagues at their workplace whereas according to only $0.5 \%$ women they face bad Attitude \& Behaviors of their male colleagues at their workplace,

Table I Women employees facing gender difference at workplace in Marathwada region

\begin{tabular}{llll}
\hline Sr. no & District & Yes & No \\
\hline I & Arangabad & 6 & 44 \\
2 & Jalna & 14 & 36 \\
3 & Beed & 16 & 34 \\
4 & Osmanabad & 22 & 28 \\
5 & Hingoli & 18 & 32 \\
6 & Nanded & 16 & 34 \\
7 & Parbhani & 21 & 29 \\
8 & Latur & 19 & 31 \\
& Total & 132 & 268 \\
& Total in Percent & $33 \%$ & $67 \%$ \\
\hline
\end{tabular}

Source: Field survey (2012-13)

Table 2 Views of working women regarding mental/physical harassment at workplace in Marathwada Region

\begin{tabular}{llll}
\hline Sr. no & District & Yes & No \\
\hline 1 & Arangabad & 8 & 42 \\
2 & Jalna & 0 & 50 \\
3 & Beed & 0 & 50 \\
4 & Osmanabad & 2 & 48 \\
5 & Hingoli & 10 & 40 \\
6 & Nanded & 12 & 38 \\
7 & Parbhani & 3 & 47 \\
8 & Latur & 5 & 45 \\
& Total & 40 & 360 \\
& Total in Percentage & $10 \%$ & $90 \%$ \\
\hline
\end{tabular}

Source: Field survey- (2012-13)

Table 3 Views of working women regarding attitude/behaviors of male colleagues at workplace in Marathwada region

\begin{tabular}{lllll}
\hline Sr. no. & District & Good & Very good & Bad \\
\hline I & Arangabad & 42 & 7 & $\mathrm{I}$ \\
2 & Jalna & 43 & 6 & $\mathrm{I}$ \\
3 & Beed & 46 & 4 & 0 \\
4 & Osmanabad & 48 & 2 & 0 \\
5 & Hingoli & 44 & 6 & 0 \\
\hline
\end{tabular}

Table Continues

\begin{tabular}{lllll}
\hline Sr. no. & District & Good & Very good & Bad \\
\hline 6 & Nanded & 34 & 16 & 0 \\
7 & Parbhani & 48 & 2 & 0 \\
8 & Latur & 40 & 10 & 0 \\
& Total & 345 & 53 & 2 \\
& $\begin{array}{l}\text { Total in } \\
\text { Percentage }\end{array}$ & $86.25 \%$ & $13.25 \%$ & $0.50 \%$ \\
\hline
\end{tabular}

Source: Field survey (2012-I3)

\section{Concluding remarks}

Over the globe today, the issue of inappropriate behavior has turned out to be pervasive violating all points of confinement and visitors. Lewd behavior at work environment makes an uncertain and antagonistic workplace, in this way debilitating ladies' interest in work and antagonistically influencing their social and monetary development. The Supreme Court of India in the year 1997 in Vishakha v. Territory of Rajasthan, recognized the gravity of lewd behavior of the working ladies at working environment and set down rules, along these lines making it obligatory for the businesses to forestall the commission of demonstrations of inappropriate behavior. In any case, India took 16years to establish the Sexual Harassment of Women at Workplace Act, 2013 for anticipation of inappropriate behavior against ladies at working environments. This papers targets featuring the present status of ladies at working environment in spite of having the enactment as of late sanctioned in India to anticipate the lewd behavior at work environment. Paper examines in detail what add up to be lewd behavior at work environment and distinctive types of inappropriate behavior. It further represents the diverse lawful arrangements in various authorizations in India including the Constitution of India to counteract such practices at work spot and talk about how the Indian legal executive in articulating the decisions on lewd behavior cases likewise depended on worldwide human rights shows and standards. It further attempts to dissect the indiscriminate in securing females at working environment and feature why it's trying to kill lewd behavior at working environments.

\section{Acknowledgments}

None.

\section{Conflicts of interest}

The authors declare that there is no conflict of interest.

\section{Funding}

None.

\section{References}

1. https://www.fcc.gov/encyclopedia/understanding-workplaceharassment-fcc-staff

2. https://en.wikipedia.org/wiki/Workplace_harassment

3. Employment discrimination

4. Workplace-Discrimination-Policies-Laws-and- Legislation

5. https://www.humanrights.gov.au/what-workplace-discriminationand-\%20harassment 